\title{
Computational Analysis on Application of Tubercles for the Performance Improvement of Horizontal Axis Wind Turbine
}

\author{
Eldhose Thomas ${ }^{1, *}$, Vivek V Kumar ${ }^{1,2}$, Dinuraj V.D ${ }^{1}$, Nithin S Lal ${ }^{1}$, Dilip A Shah ${ }^{2}$ \\ ${ }^{1}$ Department of Mechanical Engineering, Toc H Institute of Science and Technology (TIST), India \\ ${ }^{2}$ School of Aeronautical Sciences, Hindustan University, India
}

Copyright $\bigcirc 2017$ by authors, all rights reserved. Authors agree that this article remains permanently open access under the terms of the Creative Commons Attribution License 4.0 International License

\begin{abstract}
In this paper, we aim to delay the onset of stall phenomenon of the blades by applying leading edge modifications to the turbine blade. In nature, the control over the phenomenon of stall is observed in case of Humpback Whales. For these marine creatures, their flippers are having certain projections called tubercles which help it delay flow separation while performing tight underwater maneuvers while preying . These tubercles acts like a passive vortex generator at the tip of blade [2]. So we selected an optimum design from literatures to study their effects when applied to wind turbine blade airfoils. A widely used wind turbine airfoil developed by Delft University in Netherlands was chosen for this project. CFD analysis was used to evaluate and compare the aerodynamic characteristics like lift and drag coefficients of the tubercle modified and the baseline airfoil. The aerodynamic characteristics were analyzed at various angles of attack (AOA) of the airfoil and the study was mainly focused at the performance on the stall angles of the airfoil. After the numerical analysis of the tubercle modified wind turbine airfoil, it was found that the coefficient of lift was increased and coefficient of drag was reduced in the stalling angles effectively delaying the stall. Also it was observed that the tubercle modification does not have any detrimental effects on the aerodynamic performance in the pre-stall regions.
\end{abstract}

Keywords Horizontal Axis Wind Turbine, Humpback Whale Flipper, Tubercles, Lift, Drag, Stalling of Airfoil

\section{Introduction}

Wind power is one of the mainly tapped renewable energy source available. Wind turbines are the devices that are used for extracting this energy and convert to useful mechanical energy. Horizontal axis wind turbines (HAWTS) are the class of wind turbines that are used commercially owing to their several advantages over other designs. Stalling of wind turbine blade is a phenomenon which causes a sudden loss of lift and increase of drag. The stall phenomenon occurring in the turbine blades have significant unfavorable effects on the stability of the power output and the support structures. Stall also creates high fatigue loads on blade as well as the towers. Horizontal axis wind turbines (HAWT) are commercially used to generate electric power [1] by harvesting the wind energy. In this paper the main aim is to improve the aerodynamic characteristics in the stall region of wind turbine airfoil by adding leading edge tubercles.

\section{Baseline Airfoil Wind Tunnel Data}

The airfoil that we have chosen as the baseline is DU 96 W 180. It is an airfoil designed by the Delft Technical University in Netherlands [3]. The following table shows the specifications of the airfoil:

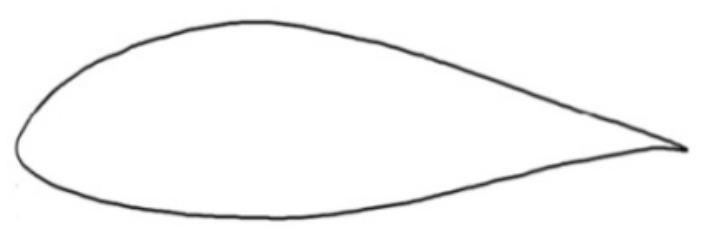

Figure 1. DU $96 \mathrm{~W} 180$ airfoil profile [3]

Table 1. Specification of DU 96 W 180 airfoil

\begin{tabular}{|c|c|}
\hline SPECIFICATION & DIMENSION \\
\hline Chord length & $1000 \mathrm{~mm}$ \\
\hline Thickness & $18 \%$ \\
\hline Span & $1.25 \mathrm{~m}$ \\
\hline
\end{tabular}




\subsection{Wind Tunnel Test Data}

The experimental testing of DU $96 \mathrm{~W} 180$ airfoil was carried out by Timmer et.al. [3] in the $1.25 \times 1.8 \mathrm{~m}$ Delft University (DU) Low-speed Wind Tunnel in Netherlands. The experimental data obtained from the testing is represented in Figure 2 which was used to validate the CFD results. The lift coefficient reaches a second maximum at $\mathrm{AOA}=40^{\circ}$ of 1.145 while at $90^{\circ} \mathrm{C}_{1}=0.106$. At $\mathrm{AOA}=45^{\circ}$ the drag coefficient equals the lift coefficient at a value of 1.154. The drag coefficient at $90^{\circ}$ is 1.914 , which is a little bit below the generally accepted flat plate value of 1.98 . This could however be expected, as the airfoil has one rounded off edge which will give a reduced wake and a small suction force as well. The value of $\mathrm{C}_{\mathrm{d}}$ at $270^{\circ}$ is 1.832 , which is lower than the value at $90^{\circ}$, being consistent with the assumption that by neglecting the downwind side the maximum $\mathrm{C}_{\mathrm{d}}$ is inversely related to the thickness (y/c-ordinate) of the nose. At $270^{\circ}$ the (thicker) upper surface of the airfoil is normal to the flow. This somewhat rounder leading edge probably results in a smaller wake and consequently in a lower drag force and a slightly higher suction force $\left(\mathrm{C}_{1}=-0.113\right)$.

\section{CFD Analysis}

Computational fluid dynamics study of the system starts with building desired geometry and mesh for modeling the domain. Generally, geometry is simplified for the CFD studies. Modeling starts with defining the boundary and initial conditions for the domain and leads to modeling the entire system domain. Finally, it is followed by the analysis of the results [10]. The physical description of rotating wind turbine becomes very complicated. Therefore, it is appropriate to do the analysis of horizontal axis wind turbine airfoils in three dimensional cases as a non-rotating entity without losing too much information [4].

\subsection{Pre-processing}

\subsubsection{Computational Domain}

The computational domain is of rectangular shape to completely enclose the airfoil. The size of the domain is larger than the wind tunnel dimensions to properly view the pressure contours and also to capture the vortices in the deep stall region.

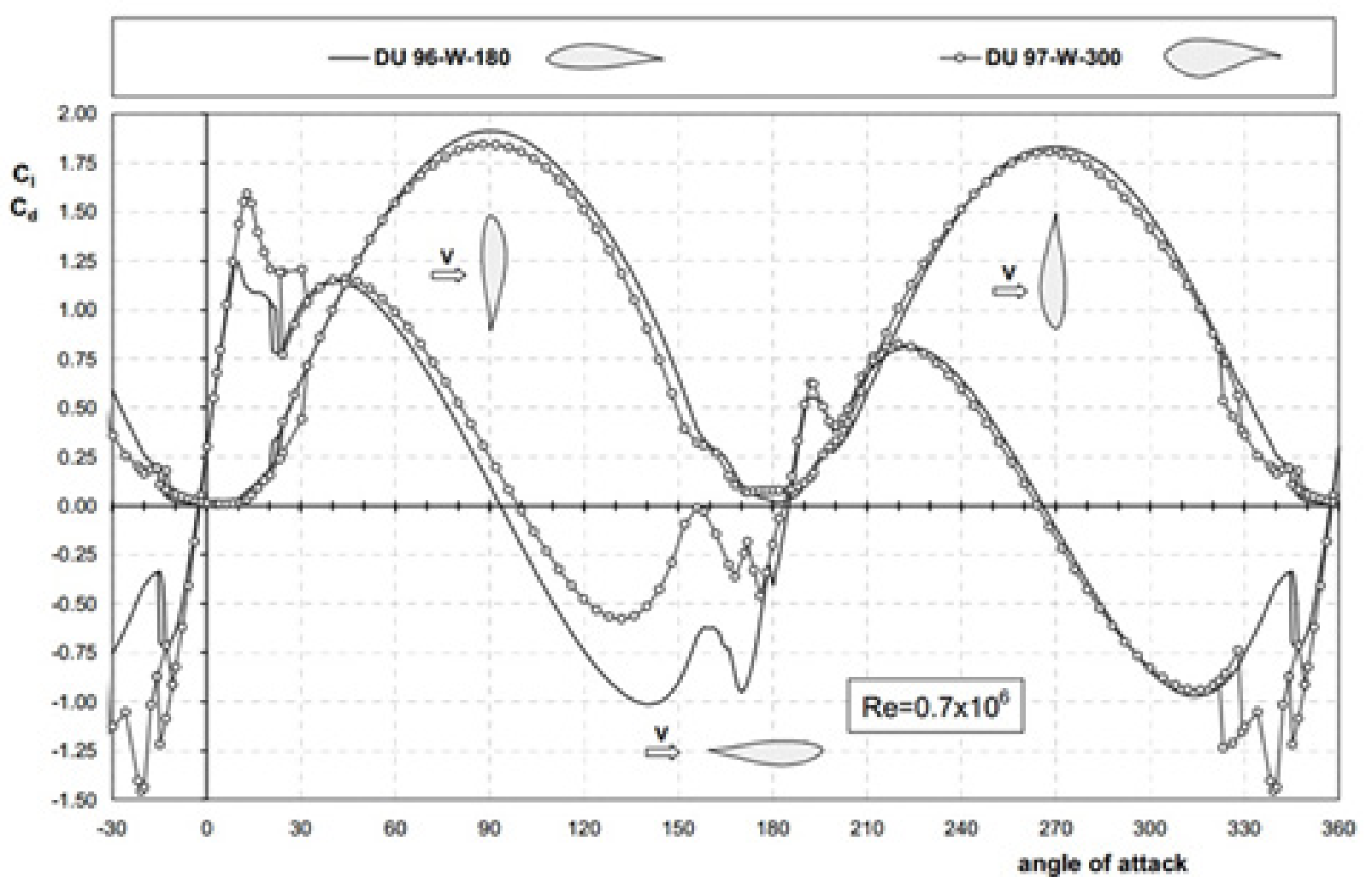

Figure 2. The performance of two DU airfoils at angles-of-attack ranging from 0 to $360^{\circ}[3]$ 


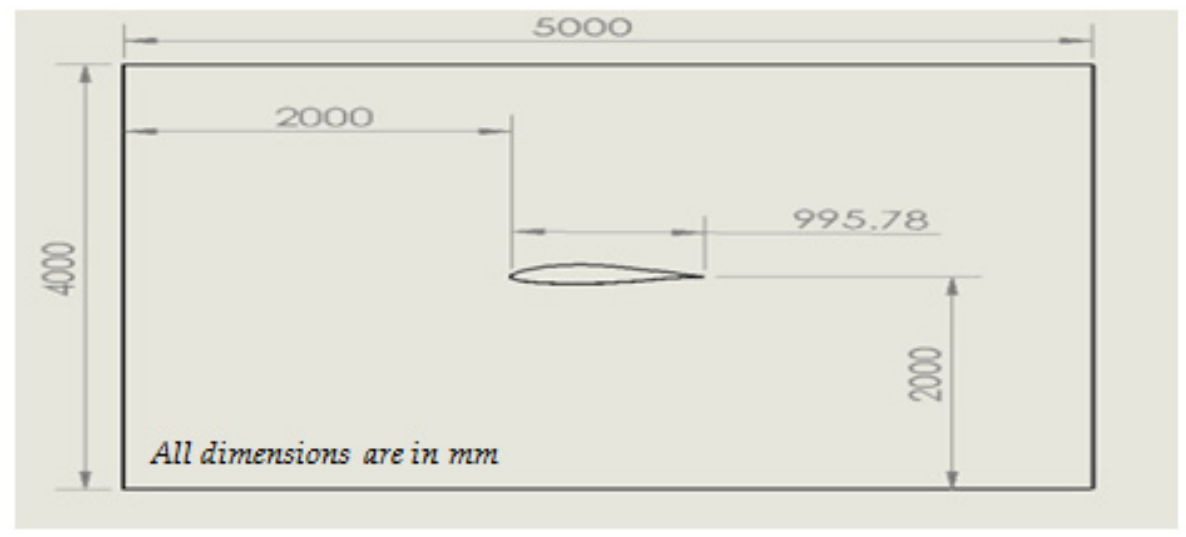

Figure 3. Computational domain

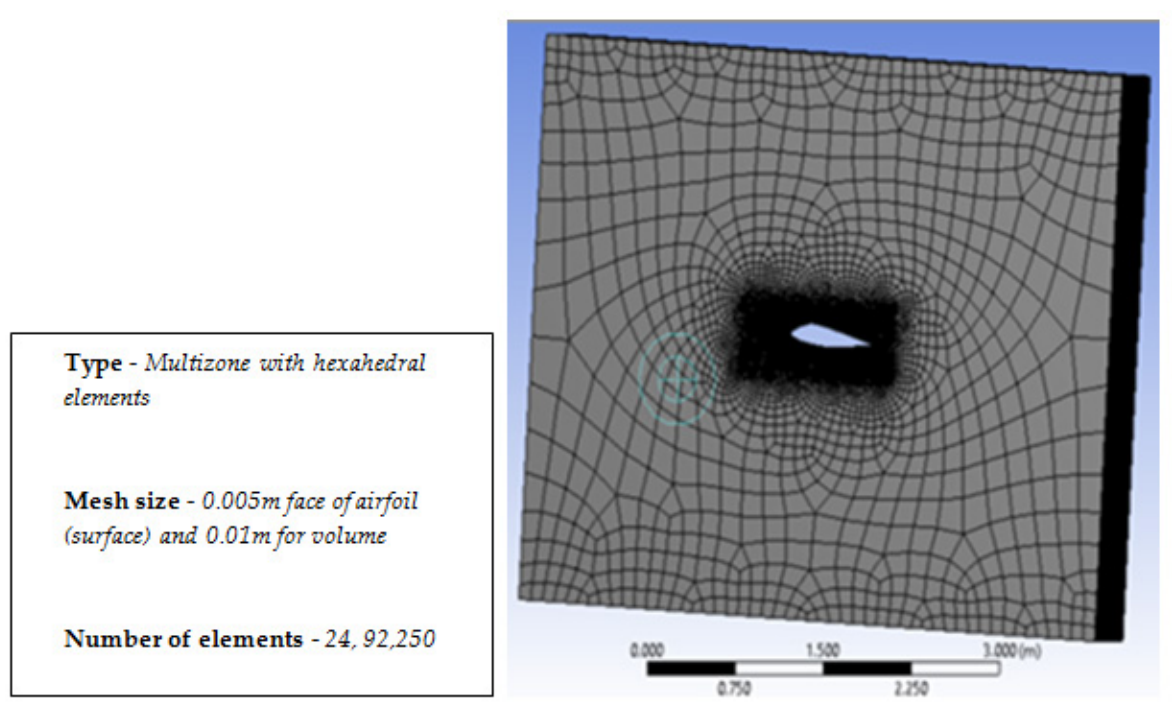

Figure 4. Meshed domain of baseline airfoil in ANSYS 15

\subsubsection{Meshing}

The mesh was completely formed with hexahedral elements having quadrilateral faces. Multizone meshing method available in "ANSYS 15 ICEM CFD" meshing tool was used to obtain the mesh around the airfoil and to generate a fine mesh near to the airfoil surface to obtain an accurate solution.

\subsubsection{Grid Independence Study}

The solution of a CFD problem is very much dependent on grid size. The grid independence test is a test that is carried out to confirm that the results obtained from the analysis are independent of the size of the grid [10]. The fine grid with 54,20,309 elements gave the most accurate result for $\mathrm{C}_{1}$ value at $8^{\circ}$ angle of attack for the unmodified airfoil. The CFD simulation in the fine grid is computationally very expensive to carry out. The coarser girds gave results that were having deviations of $11-15 \%$ from the experimental values as shown in the table below. The grid with 24, 92,250 elements was found to be the optimum grid with less deviation from the experimental values and relatively inexpensive to carry out the computation. So we have chosen that grid for our CFD analysis.

Table 2. Grid independence study

\begin{tabular}{|c|c|c|c|c|}
\hline Number of elements & 40068 & 479363 & 2492250 & 5400000 \\
\hline $\mathrm{C}_{l}$ at $8^{\circ} \mathrm{AOA}$ & 0.5 & 0.79 & 0.865 & 0.870 \\
\hline
\end{tabular}

\subsection{Processing}

\subsubsection{Numerical Methodology}

The case we have chosen here is having a three dimensional domain. The flow conditions are assumed to be steady and turbulent [8]. The computational algorithm used in the solver was 'coupled' and it was chosen after the code validation step. The turbulence model used for the analysis was SST k $\omega$ as it was found to give an accurate solution for a wide range of angles of attack of the airfoil. The SST k $\omega$ tends to be more stable in regions where there is large flow separation and eddy formation. Second order momentum [9] discretization scheme selected in order to achieve a fast convergence to the desired solution. 


\subsubsection{Boundary Conditions}

Boundary conditions are used according to the need of the model. The inlet velocities and temperature are used similar to the experimental conditions in order to have a comparison. The Reynolds number used in the wind tunnel testing was $0.7 \times 10^{6}[3]$ which was used in the CFD analysis also. Air density at $288 \mathrm{~K}$ was taken as $1.225 \mathrm{Kg} / \mathrm{m}^{3}$ and air viscosity as $1.789 \times 10^{-5} \mathrm{PaS}$. Inlet air velocity calculated from the Reynolds number and the chord length was 10.22 $\mathrm{m} / \mathrm{s}$ [7]. Chord length of the baseline airfoil was $1000 \mathrm{~mm}$.

\subsubsection{Code Validation}

The term code validation means, the process of affirming that the CFD algorithm used for solving a fluid problem is correct. In CFD, a given problem can be solved using a wide range of algorithms such as SIMPLE, SIMPLEC, PISO, COUPLED etc. Selection of the numerical method (algorithm) was done on the basis of code validation which was performed for the angle of attack of $8^{\circ}$ and $20^{\circ}$. The following table shows the result of the study conducted:

Table 3. Code validation

\begin{tabular}{|c|c|c|c|c|}
\hline AOA & SIMPLE & SIMPLEC & PISO & COUPLED \\
\hline $8^{\circ} \mathrm{C}_{l}$ & 0.867 & 0.54 & 0.867 & 0.8665 \\
$\mathrm{C}_{d}$ & 0.043 & 0.08 & 0.0432 & 0.0433 \\
\hline $20^{\circ} \mathrm{C}_{l}$ & -0.025 & -0.068 & 0.34 & 0.9212 \\
$\mathrm{C}_{d}$ & 0.64 & 0.89 & 0.84 & 0.30 \\
\hline
\end{tabular}

\subsection{Post-processing}

For the CFD simulation of the baseline airfoil the deviations from the wind tunnel data was found to be with the range of $10-15 \%$, so we can accept the CFD data.

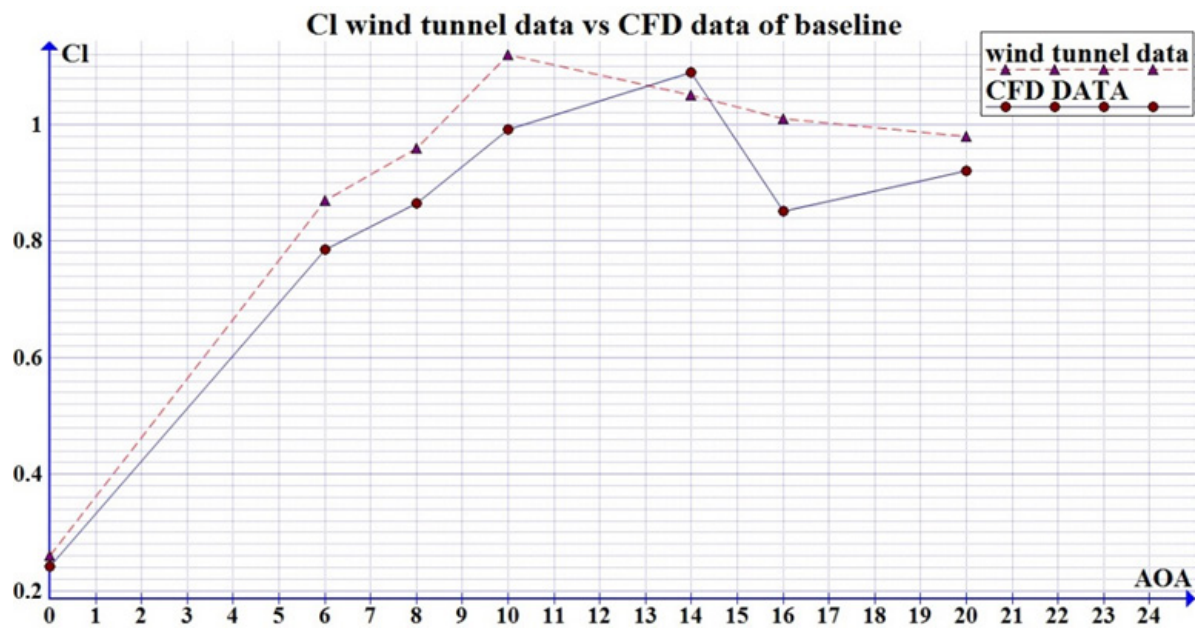

Figure 5. $\mathrm{C}_{1}$ obtained from wind tunnel and CFD

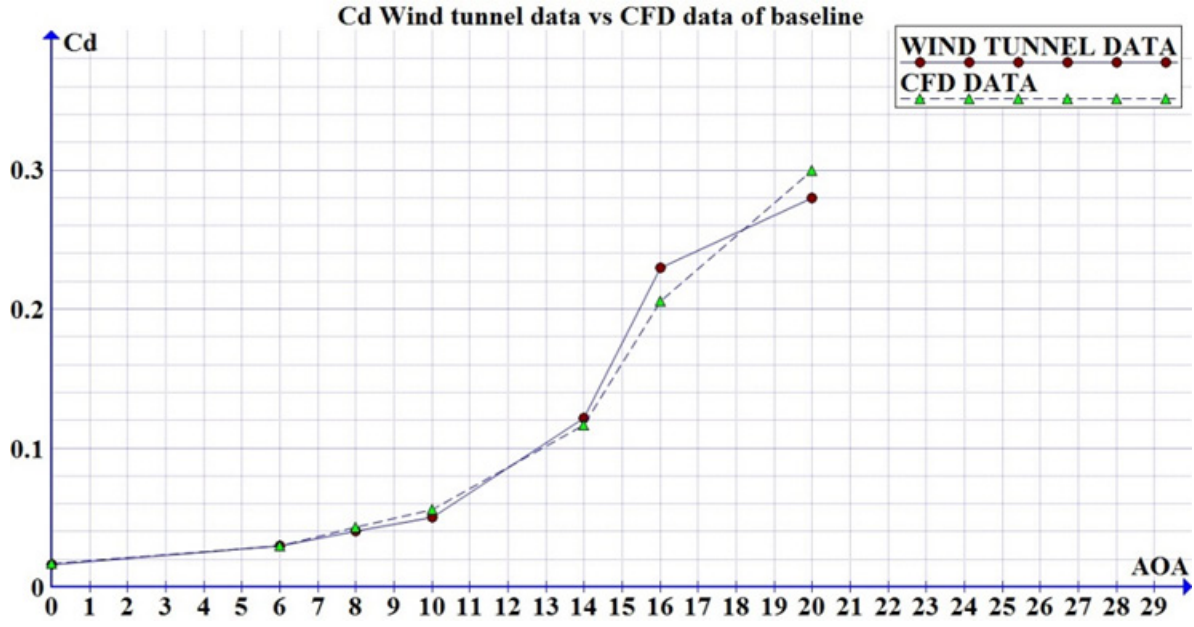

Figure 6. $C_{d}$ obtained from wind tunnel and CFD 


\section{Tubercle Geometry}

The geometry of the tubercles follows a sinusoidal pattern and their geometry was closely studied by Aftab et al., [5]. R.K. Zhang et al., [6] found in their CFD simulation of S809 wind turbine blade in which amplitude to chord ratio of 0.0250 and wavelength to chord ratio of 0.25 was giving a superior post stall performance. So we have chosen these ratios for our tubercle geometry to be applied to DU 96 W 180 airfoil.

$\begin{array}{ll}\text { A/C } & =0.0250 \\ \text { NC } & =0.25 \\ \text { Chord, } C & =1000 \mathrm{~mm} \\ \text { Amplitude, } A & \sim 25 \mathrm{~mm} \\ \text { Wavelenoth. } \lambda \sim 250 \mathrm{~mm}\end{array}$

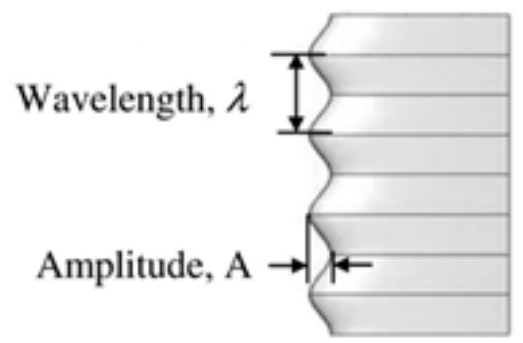

Figure 7. Tubercle modified blade geometry

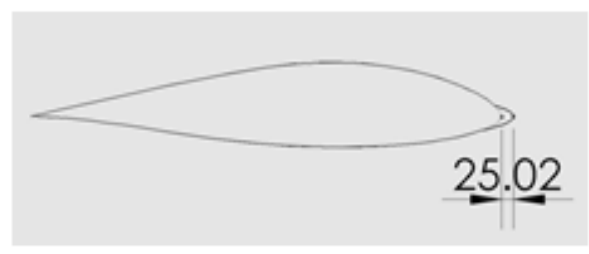

Front View

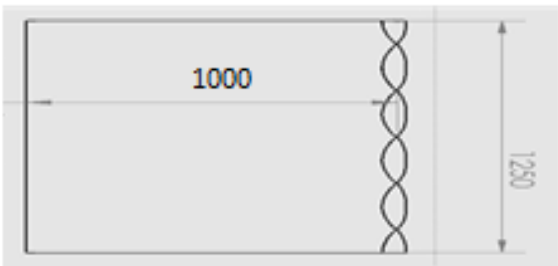

Top View

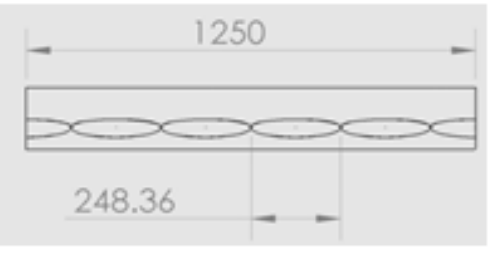

Right Side View

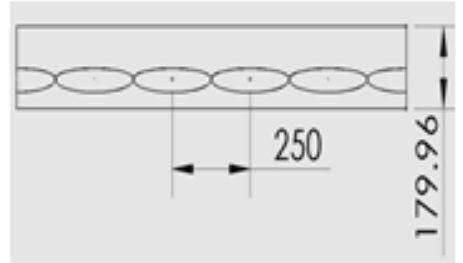

Wavelength

Figure 8. Tubercle modified DU 96 W 180 geometry details (All dimensions are in mm)

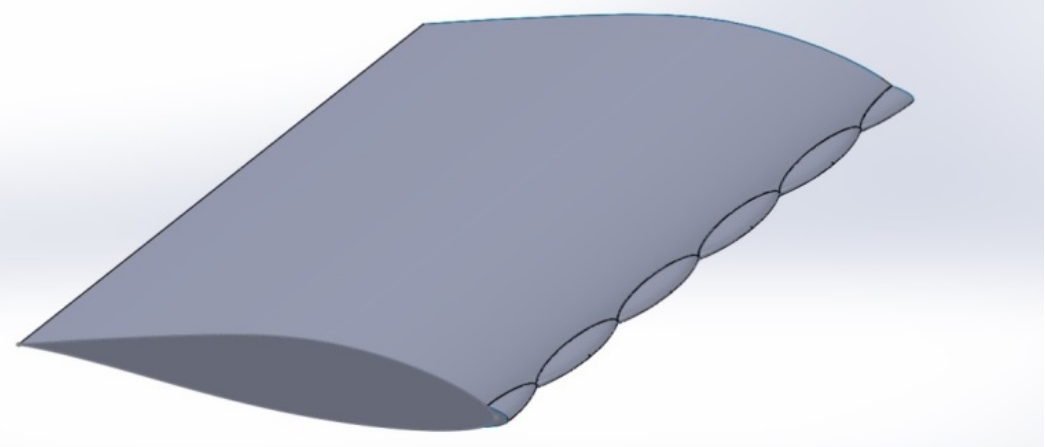

Figure 9. Tubercle modified DU 96 W 180 airfoil 3D geometry

\section{CFD Analysis of Airfoil with Leading Edge Tubercles}

The numerical simulation for DU $96 \mathrm{~W} 180$ airfoil with leading edge tubercles was done with the same numerical methodology and boundary conditions as that of the baseline airfoil. Here some additional splitting of the control volume 
was done to perform multi-zone meshing of the modified airfoil.

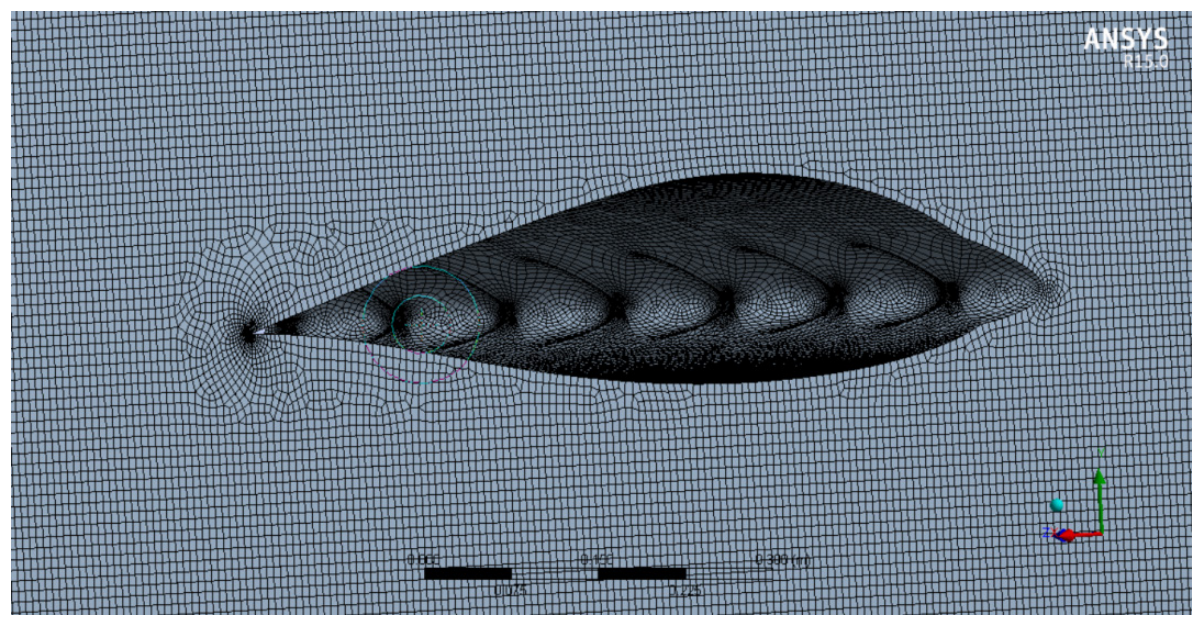

Figure 10. Meshed domain of airfoil with leading edge tubercles in ANSYS 15

\subsection{Results}

Table 4. Comparison of CFD results of modified and baseline airfoil

\begin{tabular}{|c|c|c|c|c|c|c|}
\hline AOA & $\begin{array}{c}\mathrm{C}_{l} \\
\text { baseline }\end{array}$ & $\begin{array}{c}\mathrm{C}_{l} \\
\text { modified }\end{array}$ & Improvement in \% & $\begin{array}{c}\mathrm{C}_{d} \\
\text { baseline }\end{array}$ & $\begin{array}{c}\mathrm{C}_{d} \\
\text { modified }\end{array}$ & Reduction in \% \\
\hline $0^{\circ}$ & 0.242 & 0.2517 & 3.85 & 0.017 & 0.0167 & 1.76 \\
\hline $6^{\circ}$ & 0.786 & 0.811 & 3.08 & 0.0296 & 0.0273 & 7.77 \\
\hline $8^{\circ}$ & 0.865 & 0.891 & 2.91 & 0.0433 & 0.0421 & 2.77 \\
\hline $10^{\circ}$ & 0.991 & 1.182 & 16.16 & 0.056 & 0.0424 & 24.3 \\
\hline $14^{\circ}$ & 1.09 & 1.12 & 2.67 & 0.1164 & 0.102 & 12.37 \\
\hline $16^{\circ}$ & 0.851 & 1.1668 & 27.06 & 0.206 & 0.1168 & 43.3 \\
\hline $20^{\circ}$ & 0.921 & 1.323 & 30.3 & 0.300 & 0.23 & 23.33 \\
\hline \multicolumn{2}{|c|}{ AOA } & \multicolumn{3}{|c|}{$\begin{array}{c}\mathrm{C}_{l} / \mathbf{C}_{d} \\
\text { BASELINE AIRFOIL }\end{array}$} & \multicolumn{2}{|c|}{$\begin{array}{c}\mathrm{C}_{l} / \mathbf{C}_{d} \\
\text { MODIFIED AIRFOIL }\end{array}$} \\
\hline \multicolumn{2}{|c|}{$0^{\circ}$} & \multicolumn{3}{|c|}{14.23} & \multicolumn{2}{|c|}{15.07} \\
\hline \multicolumn{2}{|c|}{$6^{\circ}$} & \multicolumn{3}{|c|}{26.55} & \multicolumn{2}{|c|}{29.70} \\
\hline \multicolumn{2}{|c|}{$8^{\circ}$} & \multicolumn{3}{|c|}{19.97} & \multicolumn{2}{|c|}{21.16} \\
\hline \multicolumn{2}{|c|}{$10^{\circ}$} & \multicolumn{3}{|c|}{17.69} & \multicolumn{2}{|c|}{27.87} \\
\hline \multicolumn{2}{|c|}{$14^{\circ}$} & \multicolumn{3}{|c|}{9.364} & \multicolumn{2}{|c|}{10.98} \\
\hline \multicolumn{2}{|c|}{$16^{\circ}$} & \multicolumn{3}{|c|}{4.131} & \multicolumn{2}{|c|}{9.9} \\
\hline \multicolumn{2}{|c|}{$20^{\circ}$} & \multicolumn{3}{|c|}{3.07} & \multicolumn{2}{|c|}{5.752} \\
\hline
\end{tabular}

\subsubsection{Coefficient of Lift $\left(C_{1}\right)$, Coefficient of Drag $\left(C_{d}\right)$ and $C_{1} / C_{d}$}

The comparison of lift coefficient of modified and baseline airfoil shown in Figure 11, gives the picture about the variation of lift coefficient under various angles of attack. The lift coefficient of the tubercle modified and the baseline airfoil shows less deviation before the pre-stall angles of attack and their effects really comes in to play in the high stall regions. When we compare the $\mathrm{C}_{1}$ values at the high angles of attack the tubercle modifications tend to reduce the effect of stall which is a sudden reduction of lift and the increase in the drag. The point of $\mathrm{C}_{1, \text { max }}$ which was at $14^{\circ}$ was found to be shifted to $20^{\circ}$ after the tubercle modification as shown in Figure 11. For other angles of attack we get an increase in the values of $\mathrm{C}_{1}$ when compared to the baseline airfoil and these observations are a clear indicator of the improvement in the lift performance of the airfoil. 


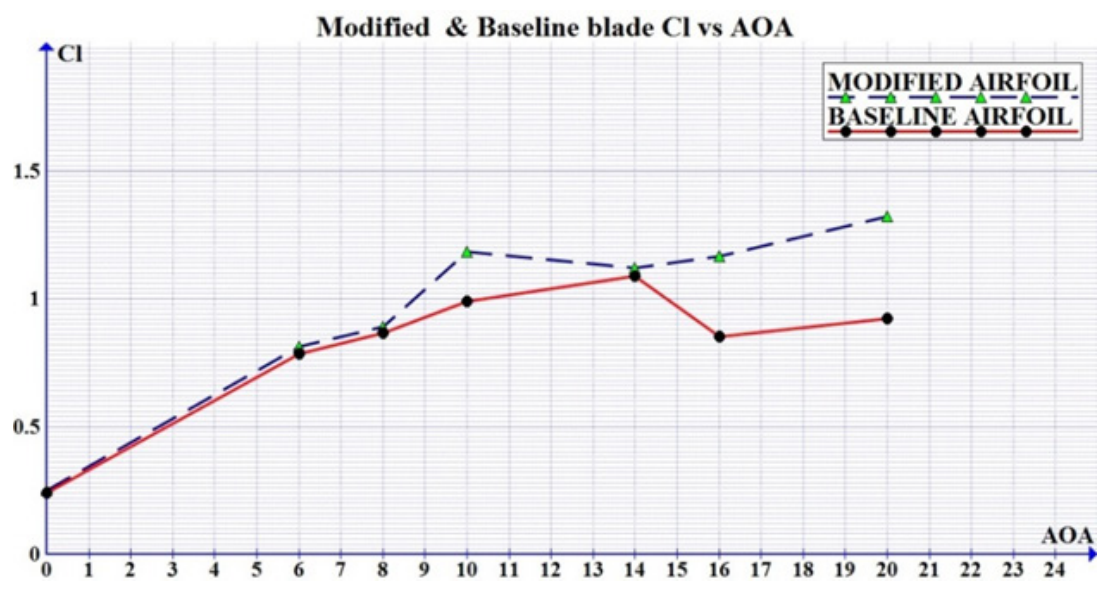

Figure 11. Comparison of lift coefficient $\left(\mathrm{C}_{1}\right)$ of modified and baseline airfoil

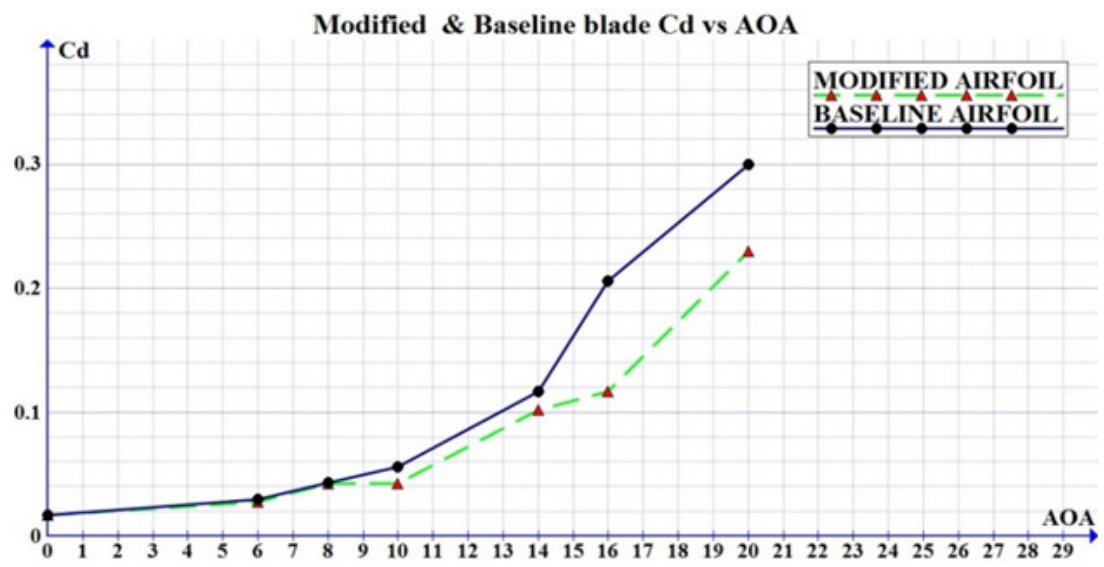

Figure 12. Comparison of drag coefficient $\left(\mathrm{C}_{\mathrm{d}}\right)$ of modified and baseline airfoil

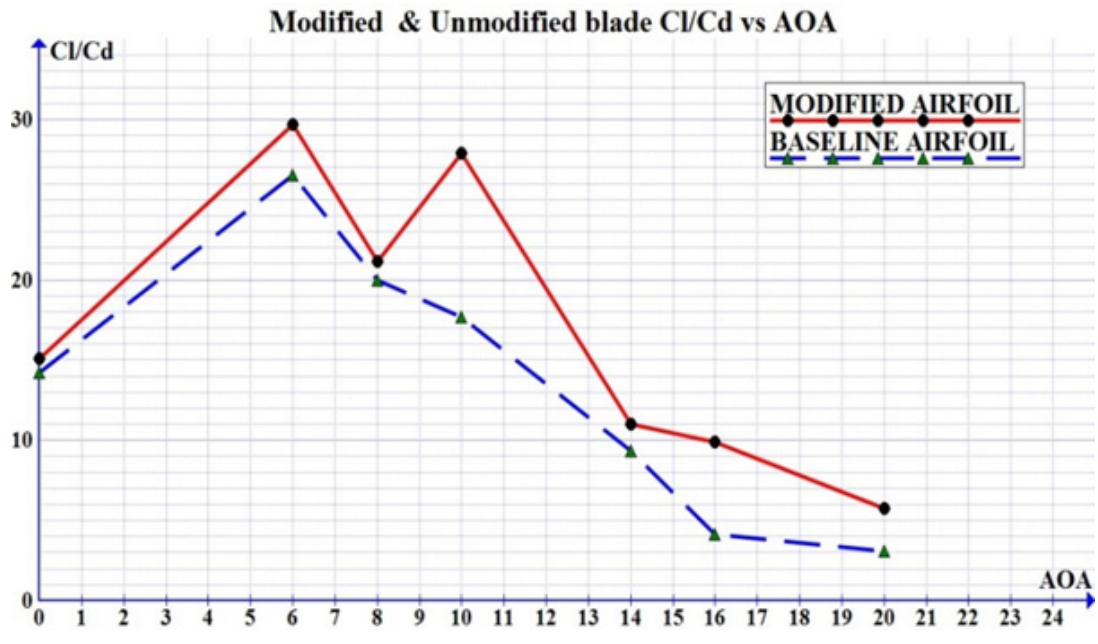

Figure 13. $\mathrm{C}_{/} / \mathrm{C}_{\mathrm{d}}$ ratio vs. AOA for the modified and baseline airfoil

The tubercle modification does not seem to increase the drag coefficient at the pre-stall region as it can be observed from Figure 12. In the post stall region the drag coefficient was found to increase dramatically for the baseline airfoil due to the onset of flow separation. The modified airfoil has reduced coefficient of drag which is caused due to the delayed flow separation from the top surface of the airfoil.

In the Figure 13 the $\mathrm{C}_{\mathrm{r}} / \mathrm{C}_{\mathrm{d}}$ ratio of the modified and the baseline airfoils are given. The ratio for the modified airfoil is found to be a larger value than that for the baseline airfoil for every angle of attack. Therefore performance deterioration is not seen anywhere after the modification, the overall aerodynamic performance is improved for the modified airfoil. The comparison of the flow streamlines for the modified and baseline airfoils is shown in the Figure 14 and we can clearly observe the flow separation is found to get delayed by a distance of $0.25 \mathrm{C}$ (C-Chord) from the leading edge for the modified airfoil for the same angle of attack of $20^{\circ}$. 


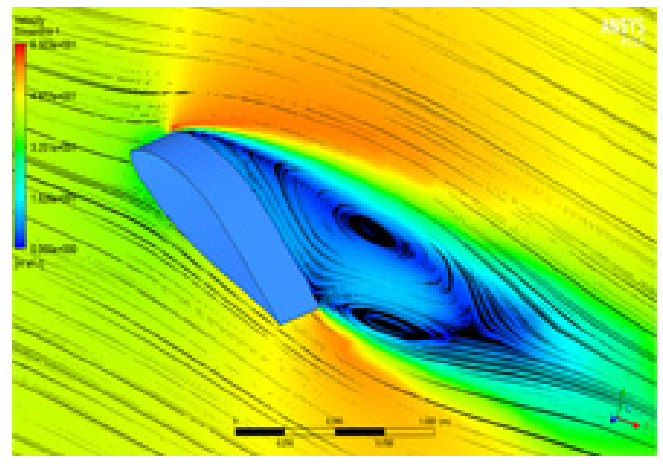

Baseline airfoil

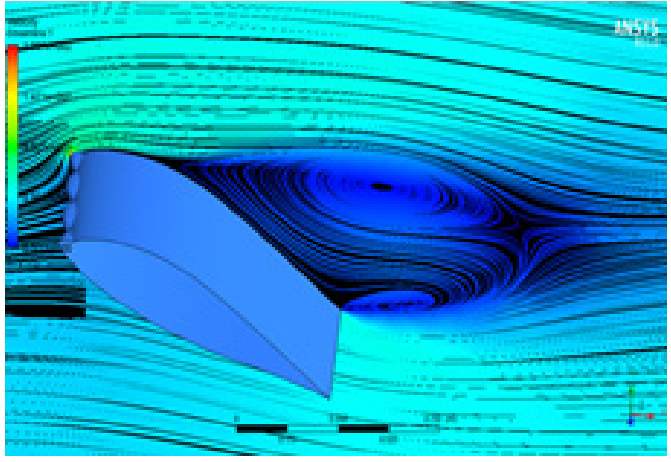

Modified airfoil

Figure 14. Streamlines showing flow separation in baseline and modified airfoils

\section{Conclusions}

Analyzed fluid flow around DU 96 W 180 airfoil and tubercle modified DU 96 W 180 airfoil successfully. Addition of tubercles has significantly reduced the coefficient of drag in the stall region of the chosen airfoil. The flow separation is delayed in the tubercle modified airfoil leading to the desired stall reduction. The sudden fall of coefficient of lift in the stall region is delayed in the tubercle modified airfoil. The lift coefficient during the stall region is increased compared to the unmodified airfoil. The drag during the pre-stall region is not much affected due to the addition of tubercles. Gradual improvement in the lift coefficient in the pre-stall region in the tubercle modified airfoil. The power generation from the modified airfoil blade will be higher than the unmodified blade due to higher coefficient of lift. Overall aerodynamic characteristics in the DU $96 \mathrm{~W} 180$ airfoil are improved by the addition of leading edge tubercles.

\section{Future Scope}

- Various shapes and dimensions can be tested incorporating tubercle modification.

- The effect of tubercles on leading edge of wings of subsonic aircrafts can be tested.

- Different blades used in wind turbine application can be tested after tubercle addition to obtain the optimum performing blade.

- Effects of addition of tubercle and dimples simultaneously on blades can be analyzed.

- Effect of tubercle modification on automobile aerodynamics can be analyzed.

\section{REFERENCES}

[1] Schubel, P. J. and Crossley, R. J. (2012). Wind Turbine Blade Design, Energies, 5, pp. 3425-3449.

[2] Kumar, V. V. and Shah, D. A. (2017). Application of tubercles in wind turbine blades: a review, Applied Mechanics and Materials, Volume 867, ISSN: 1662-7482, pp.254-260.

[3] Timmer, W. A. and van Rooij, R.P.J.O.M. (2001). Some aspects of high AOA flow on airfoils for wind turbine applications, DU WIND, the Delft University Wind Energy Research Institute.

[4] Ouahiba Guerri, Khadidja Bouhadef and Ameziane Harhad (2006). Turbulent flow simulation of the NREL S809 airfoil, Wind Engineering., Volume 30, No.4, pp. 287-302.

[5] Aftab, S. M. A., Razak, N. A., Mohd Rafie, A. S. and Ahmad, K. A. (2016). Mimicking the Humpback whale: An aerodynamic perspective, Progress in Aerospace Sciences, Volume 84, pp. 48-69.

[6] Zhang, R. K. and Wu, J. Z. (2011). Aerodynamic characteristics of wind turbine blades with sinusoidal leading edge, Wind Energy, Volume 15, Issue 3, pp. 407-424.

[7] Çengel, Y. M. and Cimbala, J. M. (2004). Fluid Mechanics: Fundamentals and Applications, 1st ed., McGraw-Hill series in mechanical engineering, ISBN 0-07-247236-7.

[8] White, F. M. (2011). Fluid Mechanics, $7^{\text {th }}$ ed., McGraw Hill Education, ISBN: $9780071333122,0071333126$.

[9] Saha, U. K. and Sukanta Roy (2012). Comparative analysis of turbulence models for flow simulation around a vertical axis wind turbine, Indo-Danish International Conference on Wind Energy: Materials, Engineering, and Policies, 22nd November -23 rd November.

[10] Hoffman, K. A. and Chiang, S. T. (2000) Computational Fluid Dynamics, 4th Ed. 